\title{
Supraglottic Laryngectomy
}

National Cancer Institute

\section{Source}

National Cancer Institute. Supraglottic Laryngectomy. NCI Thesaurus. Code C51889.

Surgical removal of the portion of the larynx superior to the true vocal cords. 